\title{
НАСЕЛЕНИЕ ДЖЕТЫАСАРСКОЙ КУЛЬТУРЫ В ЕВРАЗИЙСКОМ ПРОСТРАНСТВЕ*
}

\begin{abstract}
Изучались антропологические материалы из закрытых погребальных комплексов джетыасарской культуры. Они датируются отрезком времени от поздней античности до раннего средневековья (III-VIII вв). Суммарная краниологическая выборка включает 284 черепа (149 мужских и 135 женских). Выявлено, что все палеопопуляции джетыасарской культуры рассматриваемого периода имеет довольно близкий морфологический состав. Эти популяџии имели морфологические и генетические связи, с одной стороны, с местным оседльм и скотоводческим населением Средней Азии и Южного Казахстана, а с другой - с савроматами и сарматами Устюрта и Западного Казахстана, поздними сарматами Нижнего Поволжья и Южного Приуралья. Предлагаемый археологами подход отдельного рассмотрения закрытых погребальных комплексов как наиболее информативных для их датировки, с точки зрения полученных нами результатов является приемлемым.
\end{abstract}

Ключевые слова: античность, средневековье; археологические культуры, джетыасарская культура; погребальные комплексы; палеоантропология, краниология, краниометрические признаки, морфологические комплексы

Ссылка при цитировании: Ходжайов Т.К., Ходжайова Г.К. Население джетыасарской культуры в евразийском пространстве» // Вестник антропологии, 2021. № 1 (53). С. 202-218.

\section{Введение}

На территории Восточного Приаралья исследовано около полусотни курганных могильников, расположенных вокруг хорошо укрепленных городищ джетыасарской культуры. По данным Л.М. Левиной, время функционирования памятников охватывает период с начала железного века до конца VIII в.н.э. - начала IX вв. (Левина 1992, 1996). Она относит две трети памятников к раннему периоду до IV в.н.э., а одну треть - к позднему - до начала IX вв. (Левина 1992: 62-63). Более поздние захоронения отличаются от ранних по материальной культуре, планировке городищ и их фортификации, по характеру погребального инвентаря. На первом этапе представлено два вида захоронений: в грунтовых могилах и склепах. Наиболее ранними из них являются погребения в ямах с нишами (Левина 1992: 66; 1994: 84).

Ходжаев Тельман Касимович - д.и.н., главный научный сотрудник, Институт этнологии и антропологии РАН (Москва, Ленинский пр. 32-a). Эл.почта: telmkas@yandex.ru

Ходжайова Гальшира Кутузовна - д.и.н., бывший сотрудник, Институт Психологии и Педагогики (Москва, ул Сельскохозяйственная, 16 a). Эл.почта: telmkas@yandex.ru

* Работа выполнена по теме НИР ИЭА РАН «Эволюционный континуум рода Ното»: Подтема «Антропология древних и современных популяций» 
Погребения в ямах с боковыми нишами (и в простых ямах) вместе с погребениями в склепах являются наиболее характерными погребальными памятниками, принадлежавшими местному населению. Погребения с нишами исчезают в основном в III-1V вв., и они очень редко обнаруживаются в материалах начала V в., в отличие от погребений в склепах, которые совершаются до конца существования джетыасарской культуры. Параллельно им, начиная с V в., функционируют погребения в подбоях (Левина 1994: 84). Изучение огромного количества поселений и погребений (около тысячи) позволило ей высказать мнение о неоднократной миграции в Джетыасарский оазис различных этнических групп (Левина 1993, 1994, 1996). В некоторых случаях появление новых типов погребений исследователь связывает также и с изменениями экологической ситуации в регионе.

Миграция нового населения отмечается на разных этапах развития этой культуры, то есть несколькими волнами. Каждую такую волну автору удалось соотнести с определенным обрядом захоронения или своеобразным культурным комплексом, привнесенным из разных регионов Евразии. Так, в последние века до н.э. и первые века н.э. фиксируются довольно тесные связи с ранними культурами лесостепной полосы по берегам рек Ишим, Тобол и Иртыш (Левина 1996). В тот же период проявляются тесные контакты с населением горного Тяньшаня и ранними хуннами Забайкалья (Левина 1994; 1996). В I-IV вв. усиливаются связи с населением верховьев Таласа, Арыси и Средней Сырдарьи, существовавшие и ранее.

Следующая волна, свидетельствующая о притоке новых популяций, отмечается в IV в., она связана с известным в истории движением хуннов, а позднее - ранних тюрков (Левина 1994: 85). Кроме того, по ее материалам, в V-VI вв. выявляются существенные изменения в местной джетыасарской культуре (Левина 1996). Так, в VII в. происходит продвижение и расселение популяции джетыасарцев в правобережье дельты Амударьи, которое приводит к формированию новой кердерской культуры. Другие исследователи этого региона также считают, что джетыасарцы являются одним из важных этнических компонентов, которые приняли участие в сложении населения Кердера (Неразик 1966; Вайнберг 1999).

\section{Материалы и методы}

Краниологический материал был изучен Т.П. Кияткиной (Кияткина 1993: 224-242; 1995: 282-289). Она исследовала серию черепов из могильника Алтынасар 4 в пределах двух выделенных хронологических этапов: раннего (IV в. до н.э.- IV в.н.э.) и позднего (IV-VIII вв.). По антропологическим данным, различий между ними как по типам погребальных сооружений, так и по морфологическим комплексам не выявлено. Таким образом, заметных изменений в антропологическом составе изученного населения, морфологических комплексов или их динамики на протяжении тысячелетнего периода существования этой культуры не обнаруживается (Кияткина 1995: 240-281).

Одонтологические материалы джетыасарской культуры были изучены Г.В. Рыкушиной (Рыкушина 1993: 243-251). Она пришла к выводу, что в целом одонтологические комплексы как местных, так и пришлых групп обладают особенностями, присущими метисным популяциям, имеющим в своей основе небольшой южноевропеоидный компонент с заведомо высокой концентрацией восточных признаков различного происхождения. В одонтологических сериях из грунтовых погребений обнаружены такие 
компоненты как центральноазиатский - в популяции Косасара 2, западносибирский или уральский - в популяциях Косасара 3, Томпакасара, Бедаика (Рыкушина 1993: 194-205). Следовательно, одонтологический облик джетыасарцев, будучи метисным, на протяжении длительного исторического времени существенно не изменился.

В более позднем исследовании, проведенном Т.К. Ходжайовым и Т.П. Кияткиной (Ходжайов, Кияткина 2002: 56-85), согласно представленной Л.М. Левиной дробной периодизации могильников, основное внимание было обращено на раздельное изучение материалов из объектов, входящих в погребальный комплекс Алтынасар 4. Он состоит из двух десятков могильников. Краниологический материал каждого могильника анализировался вначале также отдельно. В последующем серии из нескольких могильников объединялись в более крупные группы по следующим критериям: близости расположения могильников, характеру сопровождающего инвентаря и конструкции погребальных сооружений.

По полученным данным, мужские и женские серии из отдельных погребений комплекса Джетыасарского урочища в период со II в. до н.э. по IV-VI вв. н.э. оказались довольно близкими по антропологическому составу. При этом обнаруживается гораздо большая гомогенность женских серий, по сравнению с мужскими. Это позволяет отметить преемственность населения джетыасарской культуры в вышеуказанный отрезок времени. Заметное увеличение монголоидной примеси у погребенного населения выявляется во II-IV вв.

В целом антропологический облик населения, оставившего эти погребения, европеоидный, мезобрахикранный, с небольшим по размеру черепом, среднешироким, высоким, лептопрозопным, резко профилированным в горизонтальной плоскости лицом, средневыступающим носом и средневысокими орбитами. Этот европеоидный тип связан с формами, известными в составе местного населения южных областей Средней Азии с глубокой древности. Монголоидный комплекс, представлен смешанными компонентами, среди которых явно выделяется центральноазиатский с присутствием западносибирского (уральского).

В последнее время появились работы, посвященные анализу хронологических рамок датировки погребальных комплексов джетыасарской культуры. Наиболее полной из них является работа С.Г. Боталова (Боталов 2009), которая основана на изучении и систематизации материалов только из погребальных комплексов, включающих 569 курганных и склепных погребений. Последующее изучение их по типам материальной культуры и конструкциям погребальных комплексов позволило сделать заключение о том, что большинство найденных предметов датируются не только V-VIII, но и IX вв. н.э., а именно они являются хронологическим индикатором. Он считает, что более ранний горизонт джетыасарской культуры, который был включен Л.М. Левиной, был зафиксирован ею в большой своей части лишь на основании поселенческих материалов. Датирующий материал, выявленный им, путем распределения его по закрытым погребальным комплексам, был обнаружен почти в 40\% погребений (246 комплексов) от общего числа их (Боталов 2009: 163-165, рис. 27).

По мнению В.Ю. Малашева и М.Г. Мошковой, хронологические рамки джетыасарских могильников, именно могильников как закрытых комплексов, могут быть отнесены к III-VII вв. н.э., судя по имеющимся надежным хронологическим индикаторам. Смещение нижней границы в сторону удревнения возможно, но обозначение определенной датировки осложнено отсутствием выразительных материалов, 
дающих надежную привязку к существующим хронологическим шкалам с соседних территорий (Малашев, Мошкова 2010: 37-56).

\section{Основные результаты}

В данной работе весь антропологический материал из могильников джетыасарской культуры (Алтынасар 4, Косасар 2 и 3, Томпакасар) рассматривается нами в несколько ином аспекте. В отличие от предыдущей работы, нами также изучались материалы только из закрытых погребальных комплексов, которые представлены суммарной краниологической выборкой без разделения на хронологические этапы. Такая общая выборка включает 284 черепа (149 мужских и 135 женских). Юношеские и детские черепа исключены из исследования (статистической обработки).

Алтынасар 4. Сборная серия состоит из 122 мужских и 112 женских черепов. Мозговая коробка мужчин и женщин мезокранная, очень высокая. Лицевая часть ортогнатная, лептопрозопная при высокой и средней ширине, сильно профилированная в горизонтальной плоскости. Нос мезоринный с высоким переносьем и носовыми костями. Орбиты гипсиконхные. Многие размеры демонстрируют значительную вариабельность в довольно широком диапазоне (табл. 1).

Таблица 1

Средние размеры и указатели черепов из могильника Алтынасар 4 (суммарно)

\begin{tabular}{|c|c|c|c|c|c|c|}
\hline \multirow{2}{*}{ № } & \multicolumn{3}{|c|}{ Мужчины } & \multicolumn{3}{|c|}{ Женщины } \\
\hline & $\mathbf{n}$ & $\mathbf{x}$ & sd & $\mathbf{n}$ & $\mathbf{x}$ & sd \\
\hline 1 & 122 & 176,8 & 8,18 & 106 & 167,3 & 7,48 \\
\hline 8 & 116 & 138,4 & 6,52 & 108 & 131,5 & 6,28 \\
\hline 17 & 99 & 141,2 & 6,14 & 98 & 136,5 & 5,86 \\
\hline 5 & 103 & 103,5 & 4,74 & 98 & 97,1 & 3,92 \\
\hline 20 & 104 & 121,9 & 6,41 & 105 & 119,2 & 5,00 \\
\hline 9 & 119 & 96,5 & 4,63 & 112 & 92,5 & 4,64 \\
\hline 10 & 111 & 118,3 & 5,95 & 105 & 112,0 & 6,37 \\
\hline 11 & 111 & 124,8 & 5,90 & 106 & 118,0 & 6,34 \\
\hline 12 & 104 & 108,2 & 5,37 & 93 & 101,9 & 5,80 \\
\hline 45 & 108 & 134,8 & 5,42 & 104 & 125,3 & 5,57 \\
\hline 40 & 91 & 99,3 & 4,91 & 87 & 94,3 & 4,43 \\
\hline 48 & 111 & 75,6 & 4,22 & 97 & 71,3 & 3,68 \\
\hline 47 & 104 & 121,4 & 7,02 & 91 & 113,6 & 6,09 \\
\hline 43 & 117 & 107,1 & 4,31 & 108 & 101,8 & 4,19 \\
\hline 46 & 111 & 98,3 & 5,04 & 104 & 92,7 & 5,03 \\
\hline 62 & 94 & 48,3 & 3,42 & 78 & 45,0 & 2,82 \\
\hline 63 & 83 & 41,7 & 2,62 & 81 & 39,8 & 2,69 \\
\hline 55 & 118 & 54,3 & 3,15 & 107 & 51,7 & 2,82 \\
\hline 54 & 117 & 25,6 & 2,00 & 105 & 24,5 & 2,12 \\
\hline
\end{tabular}


Таблица 1 (продолжение)

\begin{tabular}{l|c|c|c|c|c|c}
\hline \multirow{2}{*}{ № } & \multicolumn{3}{|c|}{ Мужчины } & \multicolumn{3}{c}{ Женшины } \\
\cline { 2 - 7 } & $\mathbf{n}$ & $\mathbf{x}$ & $\mathbf{s d}$ & $\mathbf{n}$ & $\mathbf{x}$ & sd \\
\hline 51 & 115 & 43,7 & 1,87 & 104 & 41,9 & 1,80 \\
\hline $51 \mathrm{a}$ & 98 & 39,9 & 2,69 & 79 & 38,7 & 1,98 \\
\hline 52 & 119 & 34,8 & 2,46 & 106 & 35,2 & 2,14 \\
MC & 113 & 20,1 & 2,64 & 101 & 19,3 & 2,86 \\
MS & 111 & 7,6 & 1,41 & 102 & 6,8 & 1,21 \\
\hline DC & 65 & 22,6 & 2,93 & 58 & 21,3 & 3,51 \\
\hline DS & 65 & 12,2 & 1,92 & 58 & 10,8 & 2,18 \\
\hline SC & 117 & 9,0 & 2,17 & 103 & 8,08 & 2,44 \\
\hline SS & 116 & 4,3 & 1,31 & 103 & 3,5 & 0,97 \\
\hline
\end{tabular}

Косасар 2. Краниологическая серия состоит из 13 мужских и 14 женских черепов. По основным размерам и указателям эта группа характеризуется теми же морфологическим особенностями, что и алтынасарские популяции. Можно лишь отметить, что косасарцы более широколицые, у них значительно сильнее выступают переносье, носовые кости, а также угол носа (табл. 2).

Таблица 2

Средние размеры и указатели черепов из могильника Косасар 2 (суммарно)

\begin{tabular}{|c|c|c|c|c|c|c|}
\hline \multirow{2}{*}{ № } & \multicolumn{3}{|c|}{ Мужчины } & \multicolumn{3}{|c|}{ Женщины } \\
\hline & n & $\mathbf{x}$ & sd & n & $\mathbf{x}$ & sd \\
\hline 1 & 12 & 182,3 & 8,61 & 14 & 173,1 & 6,70 \\
\hline 8 & 12 & 136,3 & 4,09 & 12 & 135,8 & 5,29 \\
\hline 17 & 7 & 140,3 & 5,19 & 10 & 137,3 & 7,57 \\
\hline 5 & 7 & 107,3 & 6,18 & 9 & 97,2 & 5,04 \\
\hline 20 & 9 & 121,0 & 2,96 & 12 & 118,3 & 7,48 \\
\hline 9 & 12 & 97,9 & 4,08 & 13 & 97,3 & 5,25 \\
\hline 10 & 11 & 119,2 & 7,04 & 12 & 114,8 & 5,31 \\
\hline 11 & 8 & 126,6 & 6,76 & 12 & 120,4 & 5,26 \\
\hline 12 & 5 & 109,4 & 5,41 & 7 & 107,6 & 3,31 \\
\hline 45 & 8 & 137,8 & 5,23 & 11 & 126,9 & 3,75 \\
\hline 40 & 3 & 102,3 & 3,06 & 9 & 90,3 & 5,24 \\
\hline 48 & 9 & 74,8 & 5,14 & 13 & 69,2 & 3,47 \\
\hline 47 & 8 & 122,8 & 6,45 & 8 & 112,4 & 3,93 \\
\hline 43 & 11 & 108,0 & 3,77 & 12 & 105,6 & 5,71 \\
\hline 46 & 11 & 97,2 & 5,15 & 14 & 94,1 & 3,72 \\
\hline 62 & 2 & 47,0 & & 8 & 43,3 & 2,87 \\
\hline 63 & 5 & 40,2 & 2,95 & 10 & 40,1 & 3,21 \\
\hline 55 & 13 & 54,3 & 3,07 & 13 & 49,8 & 3,91 \\
\hline
\end{tabular}


Таблица 2 (продолжение)

\begin{tabular}{l|c|c|c|c|c|c}
\hline \multirow{2}{*}{ No } & \multicolumn{3}{|c|}{ Мужчины } & \multicolumn{3}{c}{ Женщины } \\
\cline { 2 - 7 } & $\mathbf{n}$ & $\mathbf{x}$ & $\mathbf{s d}$ & $\mathbf{n}$ & $\mathbf{x}$ & sd \\
\hline $\mathbf{5 4}$ & 13 & 25,8 & 1,83 & 14 & 24,3 & 1,94 \\
\hline $\mathbf{5 1}$ & 11 & 43,7 & 2,80 & 13 & 41,5 & 1,71 \\
$\mathbf{5 1 a}$ & 7 & 41,7 & 1,80 & 7 & 38,9 & 1,77 \\
$\mathbf{5 2}$ & 12 & 35,1 & 1,31 & 14 & 34,7 & 2,27 \\
$\boldsymbol{M C}$ & 12 & 22,4 & 2,78 & 10 & 21,3 & 4,11 \\
$\boldsymbol{M S}$ & 12 & 8,9 & 1,73 & 10 & 7,1 & 1,77 \\
$\boldsymbol{D C}$ & 5 & 22,3 & 2,87 & 5 & 23,0 & 3,65 \\
\hline $\boldsymbol{D S}$ & 5 & 13,3 & 1,02 & 5 & 10,6 & 1,47 \\
$\boldsymbol{S C}$ & 12 & 9,5 & 1,94 & 12 & 9,1 & 2,93 \\
$\boldsymbol{S S}$ & 12 & 4,5 & 1,06 & 12 & 3,7 & 1,64 \\
\hline
\end{tabular}

Kocacap 3. Серия представлена небольшим числом черепов (5 мужских и 2 женских). В целом они характеризуются теми же особенностями, что предыдущие. От предыдущих серий отличается только женская серия, которая выделяется брахикранией (табл. 3).

Таблица 3

\section{Средние размеры и указатели черепов из могильника Косасар 3 (суммарно)}

\begin{tabular}{|c|c|c|c|c|c|c|}
\hline \multirow{2}{*}{ № } & \multicolumn{3}{|c|}{ Мужчины } & \multicolumn{3}{|c|}{ Женщины } \\
\hline & $\mathbf{n}$ & $\mathbf{x}$ & sd & $\mathbf{n}$ & $\mathbf{x}$ & sd \\
\hline 1 & 4 & 177,5 & 6,56 & 2 & 164,5 & \\
\hline 8 & 4 & 134,5 & 1,00 & 2 & 135,5 & \\
\hline 17 & 5 & 138,6 & 3,29 & 2 & 139,5 & \\
\hline 5 & 5 & 105,6 & 3,78 & 2 & 94,5 & \\
\hline 20 & 5 & 118,0 & 4,53 & 2 & 121,5 & \\
\hline 9 & 5 & 92,0 & 4,64 & 2 & 89,0 & \\
\hline 10 & 4 & 113,3 & 2,87 & 2 & 113,0 & \\
\hline 11 & 5 & 119,0 & 3,81 & 2 & 121,0 & \\
\hline 12 & 3 & 102,0 & 5,20 & 1 & 100,0 & \\
\hline 45 & 4 & 129,3 & 0,50 & 2 & 129,5 & \\
\hline 40 & 5 & 101,0 & 1,87 & 2 & 92,5 & \\
\hline 48 & 5 & 72,6 & 1,67 & 2 & 70,0 & \\
\hline 47 & 4 & 119,8 & 0,96 & 1 & 116,0 & \\
\hline 43 & 5 & 101,2 & 7,33 & 2 & 99,5 & \\
\hline 46 & 5 & 94,0 & 4,00 & 2 & 95,0 & \\
\hline 62 & 3 & 47,3 & 2,31 & 2 & 43,5 & \\
\hline 63 & 1 & 40,0 & & 2 & 39,0 & \\
\hline 55 & 5 & 53,4 & 2,51 & 2 & 53,0 & \\
\hline
\end{tabular}


Таблица 3 (продолжение)

\begin{tabular}{|c|c|c|c|c|c|c|}
\hline \multirow{2}{*}{ № } & \multicolumn{3}{|c|}{ Мужчины } & \multicolumn{3}{|c|}{ Женщины } \\
\hline & $\mathbf{n}$ & $\mathbf{x}$ & sd & $\mathbf{n}$ & $\mathbf{x}$ & sd \\
\hline 54 & 5 & 24,4 & 1,14 & 2 & 24,0 & \\
\hline 51 & 4 & 41,3 & 0,96 & 2 & 40,0 & \\
\hline $51 a$ & 4 & 38,5 & 0,58 & 2 & 37,5 & \\
\hline 52 & 5 & 34,4 & 0,55 & 2 & 34,0 & \\
\hline$M C$ & 4 & 17,3 & 3,77 & 2 & 18,5 & \\
\hline$M S$ & 4 & 8,4 & 0,63 & 2 & 6,5 & \\
\hline$D C$ & 1 & 24,0 & & 2 & 18,5 & \\
\hline$D S$ & 1 & 14,0 & & 2 & 10,5 & \\
\hline$S C$ & 4 & 8,4 & 0,51 & 2 & 6,8 & \\
\hline$S S$ & 4 & 5,8 & 1,50 & 2 & 2,7 & \\
\hline
\end{tabular}

Томпакасар. Серия включает 9 мужских и 7 женских черепов. По морфологическим характеристикам она не отличается от остальных джетыасарских (табл. 4).

Таблица 4

Средние размеры и указатели черепов из могильника Томпакасар (суммарно)

\begin{tabular}{|c|c|c|c|c|c|c|}
\hline \multirow{2}{*}{ № } & \multicolumn{3}{|c|}{ Мужчины } & \multicolumn{3}{|c|}{ Женщины } \\
\hline & $\mathbf{n}$ & $\mathbf{x}$ & sd & $\mathbf{n}$ & $\mathbf{x}$ & sd \\
\hline 1 & 8 & 177,1 & 9,28 & 7 & 170,1 & 7,01 \\
\hline 8 & 8 & 136,3 & 6,80 & 6 & 132,3 & 3,72 \\
\hline 17 & 5 & 138,0 & 3,74 & 5 & 139,6 & 4,93 \\
\hline 5 & 6 & 100,5 & 3,94 & 5 & 100,4 & 2,97 \\
\hline 20 & 7 & 119,7 & 3,35 & 6 & 118,5 & 3,89 \\
\hline 9 & 9 & 96,1 & 5,58 & 6 & 92,0 & 2,10 \\
\hline 10 & 7 & 116,9 & 7,17 & 5 & 113,4 & 3,51 \\
\hline 11 & 7 & 125,1 & 7,88 & 6 & 117,3 & 2,16 \\
\hline 12 & 6 & 105,8 & 5,67 & 5 & 102,8 & 3,11 \\
\hline 45 & 8 & 133,8 & 6,69 & 7 & 125,9 & 4,71 \\
\hline 40 & 4 & 95,3 & 4,57 & 3 & 95,3 & 4,16 \\
\hline 48 & 6 & 73,8 & 4,83 & 6 & 70,8 & 2,14 \\
\hline 47 & 4 & 113,5 & 10,38 & 3 & 114,7 & 4,0 \\
\hline 43 & 9 & 106,3 & 6,36 & 6 & 102,2 & 3,54 \\
\hline 46 & 8 & 97,8 & 7,03 & 6 & 89,3 & 4,03 \\
\hline 62 & 4 & 49,5 & 5,80 & 5 & 45,4 & 3,65 \\
\hline 63 & 6 & 41,3 & 2,07 & 5 & 38,6 & 1,95 \\
\hline 55 & 8 & 53,1 & 2,95 & 7 & 52,6 & 2,37 \\
\hline 54 & 8 & 25,1 & 1,13 & 7 & 24,6 & 1,72 \\
\hline
\end{tabular}


Таблица 4 (продолжение)

\begin{tabular}{|c|c|c|c|c|c|c|}
\hline \multirow{2}{*}{ № } & \multicolumn{3}{|c|}{ Мужчины } & \multicolumn{3}{|c|}{ Женщины } \\
\hline & $\mathbf{n}$ & $\mathbf{x}$ & sd & $\mathbf{n}$ & $\mathbf{x}$ & sd \\
\hline 51 & 8 & 42,9 & 2,75 & 7 & 42,3 & 3,15 \\
\hline $51 a$ & 5 & 39,4 & 2,51 & 6 & 38,2 & 1,72 \\
\hline 52 & 9 & 34,3 & 2,60 & 7 & 34,7 & 1,80 \\
\hline$M C$ & 7 & 20,1 & 2,73 & 6 & 20,2 & 1,83 \\
\hline$M S$ & 7 & 7,4 & 1,17 & 6 & 7,5 & 0,84 \\
\hline$D C$ & 4 & 19,8 & 0,96 & 3 & 19,3 & 1,15 \\
\hline$D S$ & 4 & 11,8 & 0,81 & 4 & 12,4 & 1,00 \\
\hline$S C$ & 8 & 10,0 & 2,45 & 7 & 9,8 & 2,64 \\
\hline$S S$ & 8 & 4,7 & 1,02 & 6 & 4,1 & 0,92 \\
\hline
\end{tabular}

Таким образом, палеопопуляции, изученные по сериям из отдельных могильников, имеют близкий морфологический состав. Существующие между ними различия могут быть связаны либо с присутствием обычая преднамеренной деформации, которая практиковалась в большей части их, либо малочисленностью отдельных серий.

Для проведения межгруппового анализа были использованы сведения, имеющиеся по 30 краниологическим сериям эпохи античности и раннего средневековья из Средней Азии и Казахстана, Нижнего Поволжья и Южного Приуралья. В программу статистического анализа были включены следующие 16 признаков: продольный диаметр (1), поперечный диаметр (8), высотный диаметр от базиона (17), скуловой диаметр (45), верхнелицевой диаметр (48), назомалярный угол (77), зигомаксиллярный угол ( $<\mathrm{ZM})$, высота носа (55), ширина носа (54), ширина орбиты от дакриона (51a), высота орбиты (52), симотическая высота (SS), симотическая хорда (SC), дакриальная высота (DS), дакриальная хорда (DC) и угол выступания носа (75 (1)).

В мужских сериях на главные компоненты (ГК 1) приходится 29,4\%, а на ГК 2 - 15,7 \% от общей изменчивости, которая в целом составила 44,7 \%. Первая компонента дифференцирует серии по вектору европеоидность - монголоидность. Она связана положительными корреляциями с высотой черепа, выступанием переносья и носовых костей, а также углом выступания носа и отрицательными - с горизонтальной профилировкой лица. Вторая компонента дифференцирует серии по таким признакам как ширина и высота лица, а также высота носа. Все эти признаки обнаруживают положительную корреляцию с ней (табл. 5, рис. 1).

Таблица 5

Элементы главных компонент для мужских серий джетыасарской культуры и сравнительные данные

\begin{tabular}{l|c|c|c|c}
\hline & $\mathbf{1}$ & $\mathbf{2}$ & $\mathbf{3}$ & $\mathbf{4}$ \\
\hline $\boldsymbol{1}$ & 0.259 & 0.480 & -0.319 & -0.142 \\
$\boldsymbol{8}$ & -0.471 & 0.388 & -0.579 & 0.325 \\
$\mathbf{1 7}$ & 0.732 & 0.008 & -0.085 & -0.352 \\
\hline $\mathbf{4 5}$ & -0.235 & $\underline{0.666}$ & -0.432 & 0.203 \\
\hline
\end{tabular}




\begin{tabular}{|c|c|c|c|c|}
\hline & & & \multicolumn{2}{|c|}{ Таблица 5 (продолжение) } \\
\hline & 1 & 2 & 3 & 4 \\
\hline 48 & -0.301 & $\underline{0.734}$ & 0.327 & -0.312 \\
\hline 55 & -0.208 & $\underline{0.690}$ & 0.598 & -0.019 \\
\hline 54 & -0.211 & -0.049 & 0.528 & 0.500 \\
\hline $51 a$ & -0.407 & 0.186 & 0.130 & 0.262 \\
\hline 52 & -0.265 & 0.300 & 0.689 & 0.132 \\
\hline 77 & $\underline{-0.797}$ & -0.182 & -0.432 & -0.001 \\
\hline$<Z m$ & $\underline{-0.848}$ & 0.041 & -0.306 & -0.133 \\
\hline$D C$ & -0.021 & 0.049 & 0.236 & -0.648 \\
\hline$D S$ & $\underline{0.800}$ & 0.148 & -0.099 & 0.331 \\
\hline$S C$ & 0.476 & -0.265 & 0.200 & 0.402 \\
\hline$S S$ & $\underline{0.833}$ & 0.319 & -0.105 & 0.089 \\
\hline $75(1)$ & $\underline{0.705}$ & 0.498 & -0.277 & -0.018 \\
\hline Charvalue & 4.710 & 2.445 & 2.362 & 1.443 \\
\hline Per cent & 29.435 & 15.281 & 14.760 & 9.018 \\
\hline
\end{tabular}

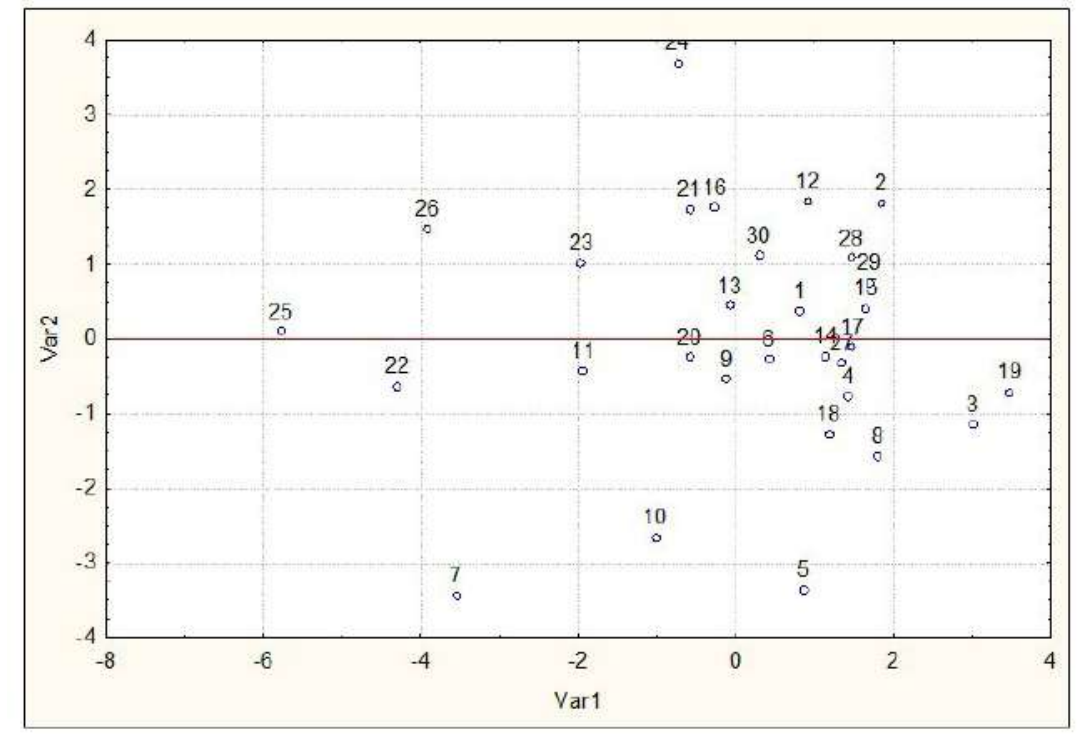

Рис. 1. Компонентный анализ мужских серий джетыасарской культуры и сравнительные данные ГК I (17, 77-, <ZM-, DS, SS, 75(1), (29,4\%); ГК II(45, 48, 55) (15,3\%); общее 44,7\%).1 -Алтынасар (сум), 2-Косасар 2 (сум), 3-Косасар 3 (сум), 4-Томпакасар (сум), 5-Борижары, 6-Каунчи I, 7-Каунчи II, 8- Каунчи III, 9-Гурмирон,

10-Кенкол-Кетменьтюбе, 11-Куюккала, 12-Токкала, 13-Казыбаба (савроматы),

14-Тумекичиджик, 15-Бабашов, 16-Мешретитахта, 17-Тузгыр, 18-Поздний Тулхар, 19-Аруктау (сум), 20-Джоондобо-Чештобе, 21-Джалпакдюбе-Туюк (Алай), 22-Кукяльда (Алай),23-Акбешим (Чу), 24-Тиктурмас (возле Джамбула), 25-Кургак-Карабент (Алай), 26-Бешкаракчи (Талас-Чу), 27-Поздние сарматы Поволжья (сборная) НЧ, 28-Поздние сарматы Поволжья (сборная) ДЧ, 29-Покровка 10, 30-Сарматы западного Казахстана. 
В плоскости компонент изучаемые серии джетыасарской культуры (Алтынасар 4, Косасар 2, Косасар 3, Томпакасар) располагаются в центре корреляционного поля, образуя объединение с сериями эпохи античности и раннего средневековья Средней Азии и Южного Казахстана, Нижнего Поволжья и Южного Приуралья. По первой компоненте от основного ядра на значительном расстоянии отделяются раннесредневековые серии из Алайской, Таласской и Чуйской долин (могильники Бешкаракчи, Акбешим, Кургак, Кукяльда), обладающие высоким сводом черепа и более выраженными европеоидными чертами. По второй компоненте от центрального ядра отделяются раннесредневековые черепа Южного Казахстана (Тиктурмас), имеющие невысокий и сравнительно узкий лицевой скелет.

Рассмотрим центральный сгусток, состоящий из серий эпохи античности и раннего средневековья. В центре основного ядра, наряду с джетыасарскими (Алтынасар 4, Косасар 2), располагаются серии каунчинской культуры Древнеташкентского оазиса (Каунчи I и II), скотоводов северной Ферганы (Гурмирон), Южного Приаралья (Тумеккичиджик, Тузгыр), Туркменистана (Бабашов), Бишкентской долины (Поздний Тулхар), савроматов Устюрта (Казыбаба) и Западного Казахстана. Здесь же находятся сборные серии (недеформированных и деформированных черепов) поздних сармат Нижнего Поволжья и Южного Приуралья (Покровка 10).

Внутри ядра различаются отдельные скопления, образованные как по первой, так и по второй компонентам. По первой компоненте выделяются два скопления. Первое из них представлено двумя сериями: из Куюккалы кердерской культуры из низовьев правобережной Амударьи и Акбешима, оставленным оседлым населением Чуйской долины. Они выделяются более выраженными европеоидными чертами. В противоположной части корреляционного поля вместе с серией из Косасара 3 располагается серия из Аруктау, оставленная скотоводческим населением Бишкентской долины.

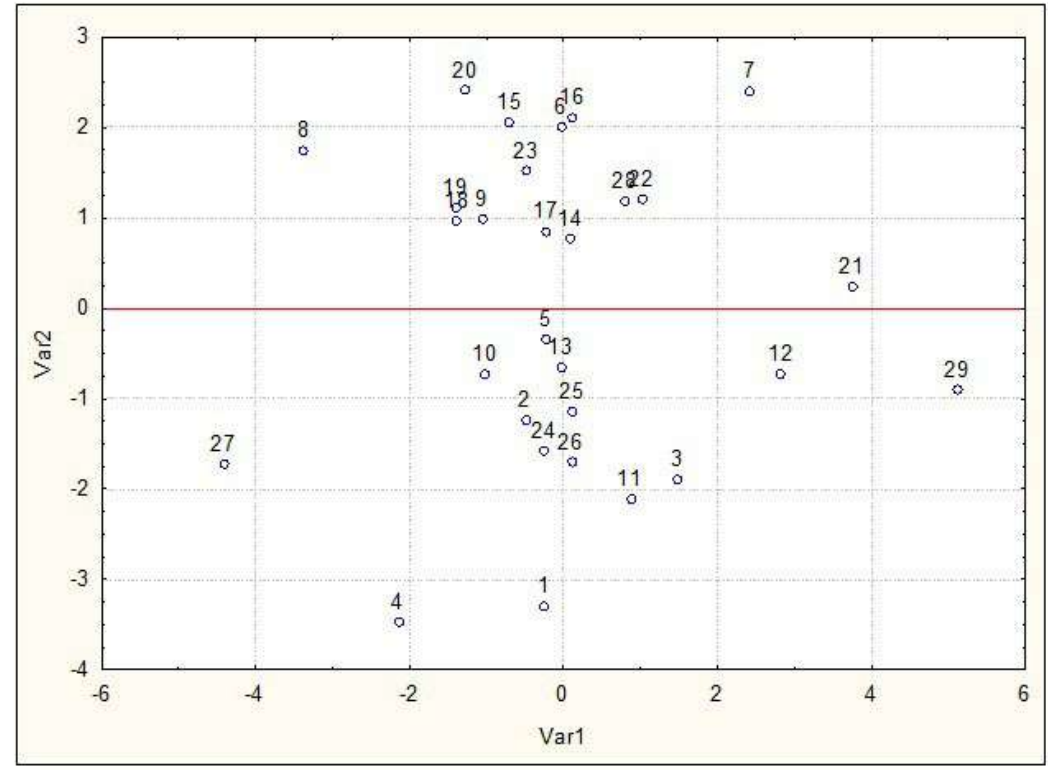

Рис. 2. Компонентный анализ мужских серий джетыасарской культуры и сравнительные данные ГК I (17, 77-, <ZM-, DS, SS, 75(1); (I-29,4\%); ГК II(45, 48, 55), (II-15,3\%); общее 44,7\%). Примечание: нумерация серий см. рис.1. 
Она характеризуется присутствием определенных монголоидных особенностей.

По второй компоненте выделяются также два скопления. Первое из них состоит из серий Бассейна средней Сырдарьи (Борижары) и Таласской долины (Кенкол, Кетменьтюбе). Они отличаются высоким и широким лицом, высоким носом. Противоположную позицию занимают серии из Косасара 2, Токкалы кердерской культуры и Мешретитахты (оставленной скотоводами южного Туркменистана), обладающие сравнительно низким и узким лицом, невысоким носом.

Результаты кластерного анализа (рис. 2) показали наиболее тесные связи популяций джетыасарской культуры, за исключением серии из Косасара 3, с поздними сарматами Нижнего Поволжья (деформированные черепа), Южного Приуралья (Покровка 10). Они все находятся на дендрограмме в одном кластере. Сарматы и савроматы Устюрта и Западного Казахстана находятся на чуть большем расстоянии, чем вышеперечисленные, но довольно близки к джетыасарским. На более отдаленном расстоянии находятся сарматы Нижнего Поволжья (недеформированные черепа). Косасар 3 отделяется от всех изученных джетыасарских из-за малой численности, но располагается среди других среднеазиатских серий.

Таблица 6

\section{Элементы главных компонент для женских серий джетыасарской культуры} и сравнительные данные

\begin{tabular}{|c|c|c|c|c|}
\hline & 1 & 2 & 3 & 4 \\
\hline 1 & 0.180 & 0.306 & $\underline{0.824}$ & -0.023 \\
\hline 8 & 0.033 & $\underline{0.842}$ & -0.125 & 0314 \\
\hline 17 & -0.559 & -0.546 & -0.120 & 0.327 \\
\hline 45 & 0.341 & 0.464 & 0.069 & 0.591 \\
\hline 48 & $\underline{0.690}$ & -0.571 & 0.034 & -0.079 \\
\hline 55 & 0.521 & -0.477 & -0.113 & 0.421 \\
\hline 54 & $\underline{0.722}$ & 0.164 & 0.320 & 0.007 \\
\hline $51 a$ & -0.168 & 0.223 & 0.105 & -0.830 \\
\hline 52 & 0.198 & -0.688 & 0.326 & 0.272 \\
\hline 77 & 0.551 & 0.408 & -0.528 & 0.157 \\
\hline$<Z m$ & 0.477 & 0.472 & 0.043 & -0.110 \\
\hline$D C$ & 0.150 & 0.059 & $\underline{0.663}$ & 0.198 \\
\hline$D S$ & -0.642 & 0.225 & 0.237 & 0.439 \\
\hline$S C$ & -0.134 & -0.103 & $\underline{0.579}$ & -0.121 \\
\hline$S S$ & -0.571 & 0.165 & 0.272 & 0.154 \\
\hline $75(1)$ & -0.760 & 0.109 & -0.108 & 0.130 \\
\hline Char.value & 3.685 & 2.913 & 2.167 & 1.826 \\
\hline Per cent & 23.032 & 18.208 & 13.543 & 11.410 \\
\hline
\end{tabular}

Таким образом, древнее население джетыасарской культуры имело морфологические, возможно и генетические, связи, с одной стороны, с оседлым и скотоводческим населением Средней Азии и Южного Казахстана, а с другой - с саврома- 
то-сарматским населением Устюрта и Западного Казахстана, поздними сарматами Нижнего Поволжья и Южного Приуралья.

Межгрупповой анализ женщин был проведен по 29 сериям, с использованием тех же признаков. На первую компоненту приходится 23,0 \%, а на вторую - 18,2 \%, что составляет 41,2 \% от общей изменчивости (табл. 6, рис.3). Положительные и высокие корреляции по первой компоненте отмечаются с высотой лица, шириной носа, a отрицательные - с дакриальной и симотической высотами и углом выступания носа.

По второй компоненте обнаруживаются положительные корреляции с шириной черепной коробки и высотой орбит. Таким образом, большинство серий находятся в центре корреляционнго поля. ГК 1 отделяет две серии с определенной степенью монголоидности (Каунчи 3 и Калкансай, курган 33) с высоким лицом, слабо выступающими переносьем и носовыми костями, малым углом выступания носа от основного ядра. Особенно удалены они от серий из Куюккалы, Кусханатау кердерской культуры и Кукяльды Алайской долины, имеющих противоположные значения данных признаков. В плоскости главных компонент «сгустки», включающие большинство серий, по ГК 1 не дифференцируются, они находятся в центре корреляционного поля.

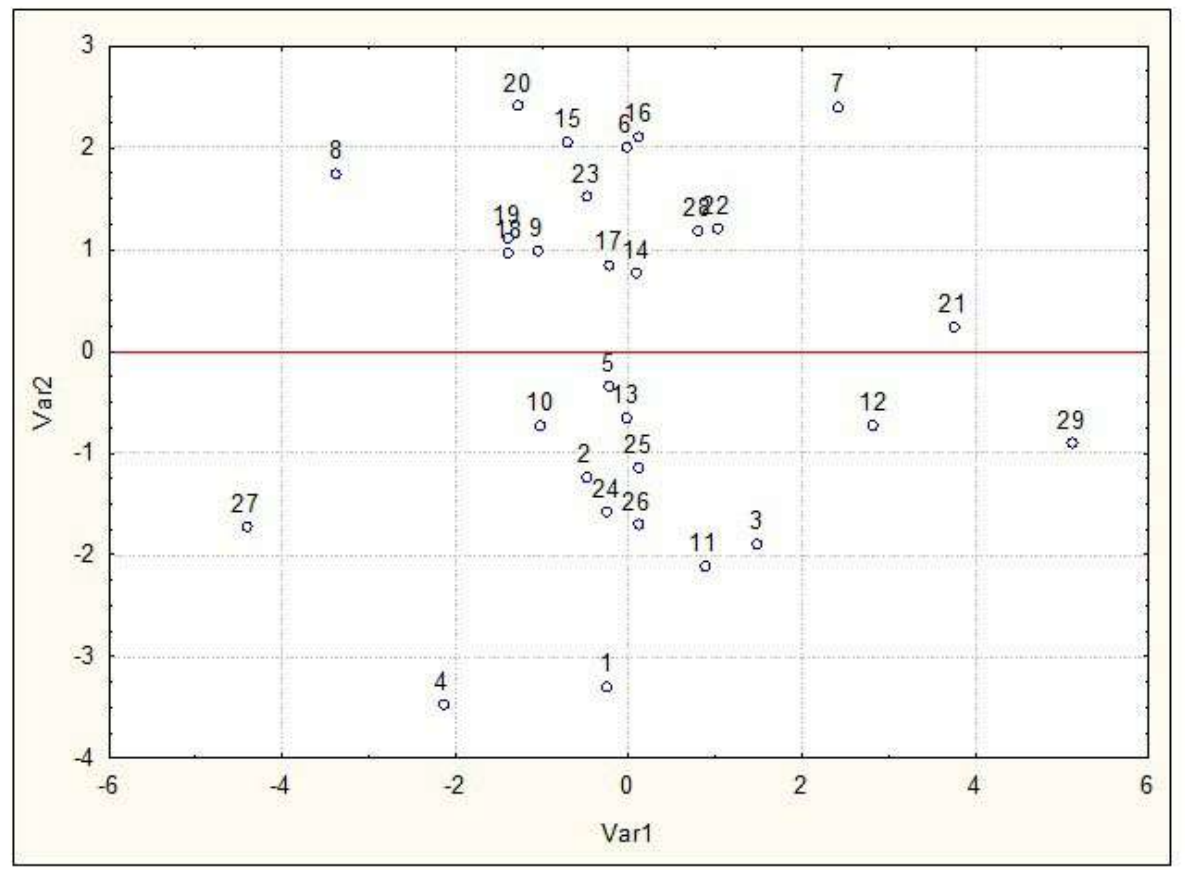

Рис. 3. Компонентный анализ женских серий джетыасарской культуры и сравнительные данные. ГК I (48, 54, DS-, SS-, 75(1)-, (I-23,0\%); ГК II (8,52), (8,2 \%); (общее 41,2\%). 1-Алтынасар (сум); 2- Косасар 2 (сум); 3-- Косасар 3 (сум); 4-Томпакасар (сум); 5-Борижары; 6-Каунчи I; 7-Каунчи II; 8-Каунчи-III; 9-Каунчи (мингурюкский комплекс); 10-Гурмирон; 11-Кенкол-Кетменьтюбе; 12-Куюккала;

13-Токкала; 14-Казыбаба (савроматы); 15-Тумеккичиджик; 16-Бабашов;

17-Мешретитахта; 18-Тузгыр; 19-Поздний Тулхар (сум); 20-Аруктау (сум);

21-Кукяльда (Алай); 22-Тиктурмас (возле Джамбула); 23-поздние сармать Поволжья (сборная), НЧ; 24-поздние сарматы Поволжья (сборная) ДЧ; 25-Покровка 10;

26-Миздахкан; 27-Калкансай, курган 33; 28-Тегирменсай; 29-Кусхана-тау. 
По второй компоненте они разделяются на два «сгустка» по таким показателям как размеры поперечного диаметра черепа и высота орбит. Однако следует отметить, что эти различия могут быть также следствием преднамеренной деформации черепной коробки. В первом «сгустке» (с широкой черепной коробкой и высокими орбитами) располагаются все серии джетыасарской культуры (Алтынасар 4, Косаcap 2 и 3, Томпакасар). В нем же находятся серии, принадлежащие скотоводческим племенам южного Казахстана (Борижары), Таласской долины (Кенкол, Кетменьтюбе), севера Ферганской долины (Гурмирон), поздним сарматам Нижнего Поволжья (сборная серия деформированных черепов) и Южного Урала (Покровка 10).

Кроме того, к ним близки раннесредневековые серии кердерской культуры правобережной Амударьи (Токкала, Куюккала) и левобережного Хорезма афригидского времени (Миздахкан). Наиболее близкими к отмеченным позднесарматским сериям оказались серии из Косасара 2 и 3. Серии других джетыасарцев (Алтынасар и Томпакасар), находясь в том же «сгустке», отличаются по размерам поперечного диаметра и высотой орбит.

Во втором «сгустке», выделяющемся по ГК 2, находятся следующие серии: из бассейна средней Сырдарьи (Каунчи I, Каунчи - Мингурюкский комплекс), раннесредневековые из южного Казахстана (Тиктурмас) и Тяньшаня (Тегирменсай), скотоводческие эпохи античности из северного (Тумеккичиджик, Тузгыр) и южного (Мешретитахта, Бабашов) Туркменистана, из Бишкентской долины южного Таджикистана (Поздний Тулхар, Аруктау). В середине его располагаются серии савроматов Устюрта (Казыбаба) и поздних сармат Нижнего Поволжья (недеформированная часть) со сравнительно узкой черепной коробкой и невысокими орбитами.

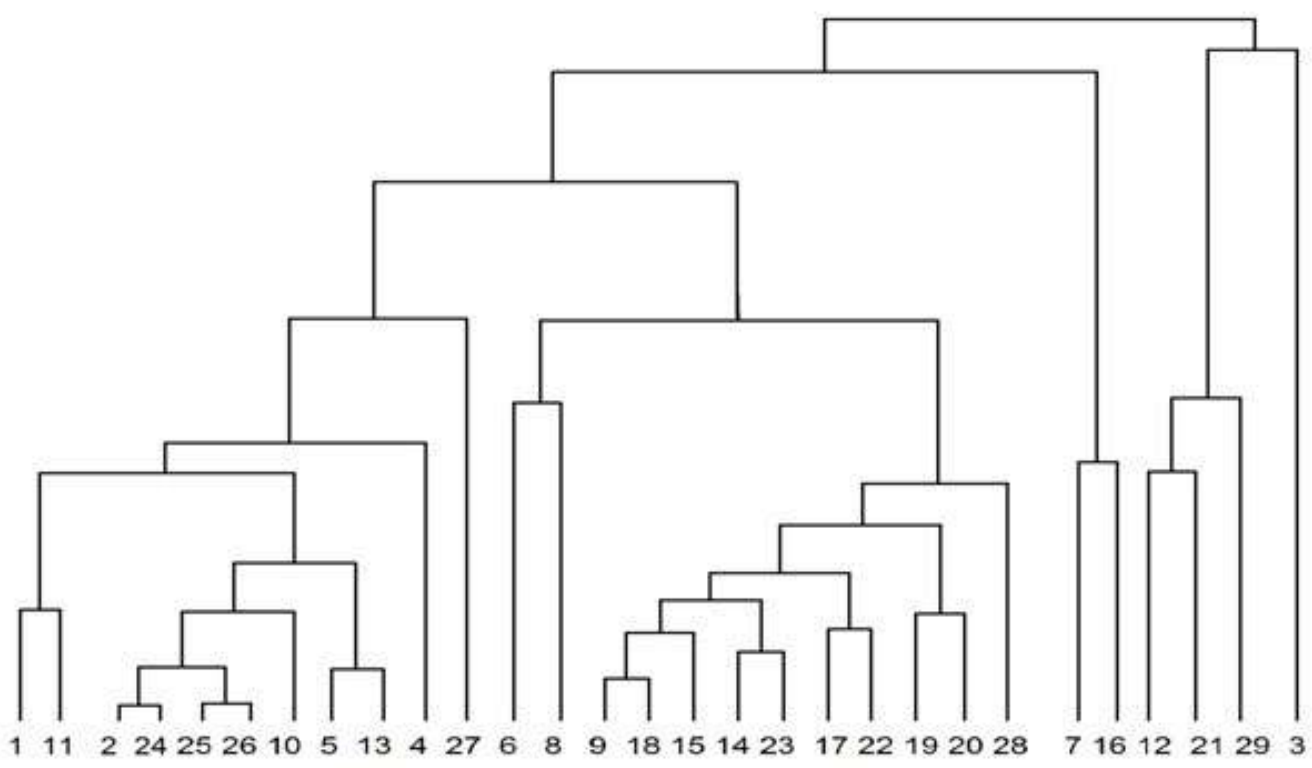

Рис. 4. Компонентный анализ женских серий джетыасарской культуры и сравнительные данные. ГК I (48, 54, DS-,SS-, 75(1)-); (I-23,0\%); (18,2\%); (общеее 41,2\%). Примечание: нумераџия серий см. рис.3. 
Результаты кластерного анализа женских серий показали, что серии, оставленные популяциями джетыасарской культуры из Алтынасара 4 и Косасара 2 очень близки к сериям поздних сармат Нижнего Поволжья (деформированные черепа) и Южного Урала (Покровка 10), то есть между ними имеются очень тесные связи (рис. 4). К вышеописанным близки также популяции из Томпакасара. Серии савроматов Устюрта (Казыбаба) и поздних сармат Нижнего Поволжья (недеформированная часть) входят в другой кластер. Таким образом, связи, выявленные с помощью данных методов, среди женских серий оказались такими же, как и среди мужских.

Как было отмечено выше, данная работа выполнялась в связи с появившейся среди археологов тенденцией к пересмотру хронологических рамок функционирования многих погребальных памятников древности и средневековья, в том числе и связанных с савромато-сарматской проблемой. С этой целью весь антропологический материал из могильников джетыасарской культуры (Алтынасар 4, Косасар 2 и 3 , Томпакасар) рассматривался суммарной выборкой с учетом типов и особенностей погребальных комплексов.

Антропологический состав населения джетыасарской культуры периодов поздней античности и средневековья оказался смешанным и морфологически многокомпонентным. В целом оно европеоидное, мезобрахикранное, с небольшими размерами черепа со среднешироким, высоким, лептопрозопным, резко профилированным в горизонтальной плоскости лицом, средневыступающим носом и средневысокими орбитами. Этот европеоидный тип связан с формами, известными в местном населении южных областей Средней Азии с глубокой древности. Монголоидный комплекс, представлен смешанными компонентами, среди которых явно выделяется центральноазиатский тип с присутствием западносибирского (уральского).

Многокомпонентность усиливается и за счет того, что большинство изученных серий эпохи античности и раннего средневековья были подвержены разным формам преднамеренной деформации головы: кольцевой, иногда комбинированной с затылочной, лобной и лобно-затылочной и теменной. В данном случае это важно отметить, так как сравниваемые серии, в том числе и сарматские, различаются по таким размерам, которые подвержены влиянию деформации.

\section{Выводы}

Таким образом, население джетыасарской культуры рассматриваемого периода (поздняя античность - раннее средневековье), судя по краниологическим материалам из всех четырех закрытых могильников, имеет довольно близкий морфологический состав. Несколько выделяется популяция из Косасара 3. Однако они в целом входят в круг оседлых и скотоводческих популяций Средней Азии эпохи поздней античности и средневековья. В результате миграции из бассейна Средней Сырдарьи в дельту Амударьи джетыасарцы принимают участие в сложении населения средневековых городищ Куюккала и Токкала.

Популяции джетыасарской культуры, за исключением серии из Косасара 3, оказались наиболее близкими к поздним сарматам Нижнего Поволжья (деформированные черепа), Южного Приуралья (Покровка 10), а также близкими к сарматам и савроматам Устюрта и Западного Казахстана. Более близкими к популяции из Косасара 3, а не к другим группам джетыасарцев, оказались сарматы Нижнего Поволжья 
(серии с недеформированными черепами). Население джетыасарской культуры рассматриваемого периода имело морфологические, возможно и генетические связи, с одной стороны, с оседлым и скотоводческим населением Средней Азии и Южного Казахстана, а с другой - с савромато-сарматским населением Устюрта и Западного Казахстана, поздними сарматами Нижнего Поволжья и Южного Приуралья.

Предлагаемый археологами подход к отдельному рассмотрению закрытых погребальных комплексов как имеющих надежные хронологические индикаторы с точки зрения полученных нами результатов является приемлемым.

\section{Научная литература}

Боталов С.Г. Гунны и тюрки (историко-археологическая реконструкция). Челябинск, ООО «ЦИКР «Рифей», 2009.

Вайнберг Б.И. Этнография Турана в древности. VII в.до н.э. - VIII вв. н.э. М.: Восточная литература, 1999.

Кияткина Т.П. Краниологический материал из склепов могильников Алтынасар 4, Томпакасар и Косасар // Низовье Сырдарьи в древности. Вып. II. Джетыасарская культура. Часть 1. СклепЫ. М.: ИЭА РАН, 1993. С. 224-242.

Кияткина Т.П. Краниологический материал из Томпакасарского могильника // Низовье Сырдарьи в древности. Вып.V. Джетыасарская культура. Часть 5. М.: ИЭА РАН, 1995. C. 282-289.

Кияткина Т.П. Краниологические исследования из могильников Алтынасар 4 // Низовье Сырдарьи в древности. Вып.V. Джетыасарская культура. Часть 5. М.: ИЭА РАН, 1995. C. $240-281$.

Левина Л.М. Памятники джетыасарской культуры середины I тыс. до н.э. - I тыс. н.э. // Археология СССР. Степная полоса Азиатской части СССР в скифо-сарматское время. М.: Наука, 1992. С. 61-72.

Левина Л.М. Джетыасарские склепы // Низовье Сырдарьи в древности. Вып. II. Джетыасарская культура. Часть 1. М.: ИЭА РАН, 1993. С. 33-198.

Левина Л.М. Могильники Алтынасар 4 // Низовье Сырдарьи в древности. Вып. IV. Джетыасарская культура. Часть 3-4. М.: ИЭА РАН, 1994.

Левина Л.М. Этнокультурная история Восточного Приаралья: I тыс. до н.э.- I тыс.н.э. М.: ИЭА РАН, 1996.

Малашев В.Ю., Мошкова М.Г. Происхождение позднесарматской культуры (к постановке проблемы) // Становление и развитие позднесарматской культуры (по археологическим и естественнонаучным данным). Материалы семинара Центра изучения истории и культуры сарматов. Выпуск III. Волгоград, Волгоградский государственный университет, 2010. С. 37-56.

Малашев В.Ю., Яблонский Л.Т. Степное население Южного Приуралья в позднесарматское время (по материалам могильника Покровка 10). М.: Издательская фирма «Восточная литература» $\mathrm{PAH}, 2008$.

Неразик Е.Е. Сельские поселения афригидского Хорезма. М.: Наука, 1966.

Рыкушина Г.В. Одонтологическая характеристика черепов из склепов джетыасарской культуры (Алтынасар 4, Томпакасар, Косасар 3) // Низовье Сырдарьи в древности. Вып.ІІ. Джетыасарская культура. Часть 1. Склепы. М.: ИЭА РАН, 1993. С. 243-252.

Рыкушина Г.В. Материалы по одонтологии джетыасарской культуры. Грунтовые погребения могильников Косасар 2, Косасар 3, Томпакасар, Бедаикасар // Низовье Сырдарьи в древности. Вып. III. Джетыасарская культура. Часть 2. Могильники Томпакасар и Косасар. М.: ИЭА РАН, 1993. С. 195-205.

Ходжайов T.К., Кияткина Т.П. Археолого-антропологическая характеристика населения джетыасарской культуры Восточного Приаралья // На путях биологической истории человечества. Сборник статей. Том ІІ. М.: ИЭА РАН, 2002. С. 56-85. 
Khodzhayov Telman K., Khodzhayova Galshira K.

DOI: $10.33876 / 2311-0546 / 2021-53-1 / 202-218$

\section{Jetyasar population in Eurasia}

Anthropological materials from closed burial complexes of the Jetyasar culture were studied. They date back to the time span from late antiquity to the early Middle ages (III-VIII centuries). The total craniological sample includes 284 skulls (149 male and 135 female). It was revealed that all the paleopopulations of the Jetyasar culture of the period under consideration have a fairly close morphological composition. These populations had morphological and genetic ties, on the one hand, with the local sedentary and pastoral population of Central Asia and South Kazakhstan, and on the other, with the Savromats and Sarmatians of Ustyurt and Western Kazakhstan, the late Sarmatians of the Lower Volga and Southern Urals. The approach proposed by archaeologists to consider separately closed burial complexes as the most informative for their dating is acceptable, according to our results.

Key words: Antiquity, middle ages; archaeological cultures, Jetyasar culture; burial complexes; paleoanthropology, craniology, craniometric traits, morphological complexes

For Citation: Khodzhayov T.K., G.K. Khodzhayova. 2021. Jetyasar population in Eurasia. Herald of Anthropology (Vestnik Antropologii) 1 (53): 202-218

Khodzhayov Telman K - Doctor of Historical Sciences, Institute of Ethnology and Anthropology, RAS (Moscow, Leninsky Pr. 32-a). E-mail: telmkas@yandex.ru

Khodzhayova Galshira K. - Doctor of Historical Sciences, former employee of the Institute of Psychology and Pedagogy (Moscow, ul. Agricultural, 16 a). E-mail: telmkas@yandex.ru.

The work was carried out on the topic of the Research Institute of the IEA RAS "The evolutionary continuum of the genus Homo": Sub-topic "Anthropology of ancient and modern populati"

\section{References}

Botalov, S.G. 2009. Gunny i tiurki (istoriko-arkheologicheskaia rekonstruktsiia). [Huns and Turks (historical and archaeological reconstruction)]. Cheliabinsk: OOO "TsIKR "Rifei":

Khodzhaiov, T.K., and T.P. Kiiatkina. 2002. Arkheologo-antropologicheskaia kharakteristika naseleniia dzhetyasarskoi kul'tury Vostochnogo Priaral'ia. [Archaeological and anthropological characteristics of the population of the Djetyasar culture of the Eastern Aral Sea region]. Na putiakh biologicheskoi istorii chelovechestva. Sbornik statei. Vol. II, 2: 56-85. Moscow: IEA RAN.

Kiiatkina, T.P. 1995. Kraniologicheskie issledovaniia iz mogil'nikov Altynasar 4. [Craniological research from the Altinasar 4 burial grounds]. Nizov'e Syrdar'i $v$ drevnosti. Vol. V. Dzhetyasarskaia kul'tura. Pt. 5, 5 (5): 240-281. Moscow: IEA RAN.

Kiiatkina, T.P. 1995. Kraniologicheskii material iz Tompakasarskogo mogil'nika [Craniological material from the Tompakasar burial ground]. Nizov'e Syrdar'i $v$ drevnosti. Vol. V. Dzhetyasarskaia kul'tura. Pt. 5, 5 (5): 282-289. Moscow: IEA RAN,

Kiiatkina,T.P. 1993. Kraniologicheskii material iz sklepov mogil'nikov Altynasar 4, Tompakasar i Kosasar [Craniological material from the crypts of Altynasar 4, Tompakasar and Kosasar burial grounds]. Nizov'e Syrdar'i v drevnosti. Vol. II. Dzhetyasarskaia kul'tura. Pt. 1. Sklepy, 2 (1): 224-242. Moscow: IEA RAN.

Levina, L.M. 1992. Pamiatniki dzhetyasarskoi kul'tury serediny I tys. do n.e. - I tys. n.e. [Monuments of the Dzhetasar culture of the middle of the 1st millennium BC - 1st millennium AD]. Arkheologiia SSSR. Stepnaia polosa Aziatskoi chasti SSSR v skifo-sarmatskoe vremia, 61-72. Moscow: Nauka.

Levina, L.M. 1993. Dzhetyasarskie sklepy. [Dzhetyasar Crypts]. Nizov'e Syrdar'i v drevnosti. Vol. 
II. Dzhetyasarskaia kul tura. Pt. 1, 2 (1): 33-198. Moscow: IEA RAN.

Levina, L.M. 1994. Mogil'niki Altynasar 4. [Altynasar Cemetery 4]. Nizov'e Syrdar'i v drevnosti. Vol. IV. Dzhetyasarskaia kul tura. Pt. 3-4, 4 (3-4). Moscow: IEA RAN.

Levina, L.M. 1996. Etnokul'turnaia istoriia Vostochnogo Priaral'ia: I tys. do n.e. - I tys.n.e. [Ethnocultural history of the Eastern Priaralye: 1st millennium BC - 1st millennium AD]. Moscow: IEA RAN.

Malashev, V.Yu., and L.T. Yablonskii. 2008. Stepnoe naselenie Iuzhnogo Priural'ia $v$ pozdnesarmatskoe vremia (po materialam mogil'nika Pokrovka 10). [The steppe population of the Southern Urals in the Late Sarmatian period (based on materials from the Pokrovka 10 burial ground)]. Moscow: Izdatel'skaia firma "Vostochnaia literature" RAN.

Malashev, V.Yu., and M.G. Moshkova. 2010. Proiskhozhdenie pozdnesarmatskoi kul'tury (k postanovke problemy). [The origin of the late Sarmatian culture (to the problem statement)]. Stanovlenie i razvitie pozdnesarmatskoi kul'tury (po arkheologicheskim i estestvennonauchnym dannym). Materialy seminara Tsentra izucheniia istorii i kul'tury sarmatov. Vol. III. Volgograd: Volgogradskii gosudarstvennyi universitet 3: 37-56.

Nerazik, E.E. 1966. Sel'skie poseleniia afrigidskogo Khorezma. [Rural settlements of Afrigid Khorezm]. Moscow: Nauka.

Rykushina, G.V. 1993. Materialy po odontologii dzhetyasarskoi kul'tury. Gruntovye pogrebeniia mogil'nikov Kosasar 2, Kosasar 3, Tompakasar, Bedaikasar. [Materials on the odontology of the Dzhetyasar culture. Ground burials of the burial grounds of Kosasar 2, Kosasar 3, Tompakasar, Bedaikasar]. Nizov'e Syrdar'i v drevnosti. Vol. III. Dzhetyasarskaia kul'tura. Pt. 2. Mogil'niki Tompakasar i Kosasar, 3 (2): 195-205. Moscow: IEA RAN.

Rykushina, G.V. 1993. Odontologicheskaia kharakteristika cherepov iz sklepov dzhetyasarskoi kul'tury (Altynasar 4, Tompakasar, Kosasar 3). [Odontological characteristics of skulls from crypts of the Dzhtyasar culture (Altynasar 4, Tompakasar, Kosasar 3)]. Nizov'e Syrdar'i v drevnosti. Vol. II. Dzhetyasarskaia kul'tura. Pt. 1. Sklepy: 243-252. Moscow: IEA RAN.

Vainberg, B.I. 1999. Etnografiia Turana v drevnosti. VII v.do n.e. - VIII vv. n.e. [Ethnography of Turan in antiquity. VII century BC - VIII centuries. AD]. Moscow: Vostochnaia literature. 